\title{
UN TIENTO A LA PORFÍA. Betis-Sevilla, cismogénesis y estereotipo
}

\author{
Rufino ACOSTA NARANJO \\ Universidad de Sevilla \\ racosta@us.es
}

\begin{abstract}
A TENT TO THE PORPHY. Betis-Sevilla, cismogenesis and stereotype
Resumen: La rivalidad entre dos equipos de fútbol de una misma ciudad es un fenómeno bastante frecuente en todo el mundo. La división entre esas dos mitades está cargada de significaciones de diverso tipo que trascienden lo meramente deportivo. Constatando esa misma dinámica en el caso del Sevilla Fútbol Club y el Real Betis Balompié, existe sin embargo una singularidad relevante, ya que uno de los clubes encarna otros imaginarios que van más allá de lo estrictamente sevillano, ya que se identifica más con determinado estereotipo de Andalucía.

Abstract: The rivalry between two football teams of the same city is a fairly common phenomenon throughout the world. The division between these two halves involves meanings of various kinds which merely transcends sport dimension. Noting that same dynamic in the case of Sevilla Football Club and Real Betis Balompié, there is nevertheless a relevant singularity since one of such clubs embodies other imaginaries that go beyond strictly sevillian characteristics, being also identified with a certain image of Andalusia.
\end{abstract}

Palabras clave: Fútbol. Cismogénesis. Andalucía. Estereotipos. Identificaciones Football. Schismogenesis. Andalusia. Stereotypes. Identifications 
Quien no comprende la razón del rito, (...) nunca conocerá la humana altura.

Releía los versos de Julio Martínez Mesanza, amputados y malversados en su literalidad y sentido, cuando andaba queriendo escribir estas letras que durante mucho he postergado, por desidia, desmemoria y falta de indagación sistemática. Es sobre todo por esto último que no pretendo otra cosa que echar un tiento a la interpretación de la pugna entre los dos equipos de fútbol de Sevilla desde la perspectiva de los imaginarios sociales. Y es así porque, aunque profanos y burdos muchas veces, los lances del fútbol participan bastante de una dimensión ritual, y es este sin duda el deporte que más ampliamente puede hablarnos de los valores de nuestra sociedad. A menudo pierde centralidad su condición propiamente deportiva y pasa a expresar más bien otras cosas, a ser un referente simbólico, de identificación personal y colectiva. En el caso específico de Sevilla, mucho se ha dicho sobre la rivalidad futbolística, pero echo en falta una mirada, no a la supremacía de uno u otro club, a la fuerza del sentimiento de cada cual o su arraigo en la ciudad, sino al imaginario respectivo que evocan o dicen evocar las dos entidades, y a su naturaleza diferente.

Parto de la premisa de sobra conocida en otros ámbitos, ya sean deportivos o festivos, de que la rivalidad, las dualidades, lejos de separar a una comunidad en dos mundos vueltos de espaldas, pueden dar fe de la adscripción, ser una evidencia de que se está en el universo social del lugar, que se manejan las claves cómplices de la pertenencia. Para mí fue sin duda alguna Gregory Bateson quien más luz arrojó sobre ello en su estudio sobre las ceremonias naven. Con el concepto de cismogénesis fijó ese proceso por el cual a través de la división en dos mitades se conforma lo local, se articula social e ideológicamente su mundo vital. En lugar de partir, el cisma ritual unifica. Con las evidentes diferencias que a nadie pueden escapárseles, la adscripción a uno de los dos equipos es una manera de sentirse parte de la vida y el mundo sevillano.

Disputas de este tipo son de sobra conocidas en el ámbito del deporte, pero lo que a mí me resulta más sugerente es ver cómo, en nuestro caso, se trata de una dualidad que no permite medir a los participantes. Las categorías simbólicas que uno y otro amparan son de distinto orden pero, sobre todo, estas se vinculan a imaginarios de distinta escala territorial. En efecto, un equipo de fútbol, o ciertos equipos de futbol, encarnan estereotipos, un conjunto de rasgos que se compadecerían con una imagen colectiva, a la cual se adscribirían las gentes. Adelanto que no me parece demasiado relevante que esa identificación, esa representación o autorrepresentación, se avenga o no con la realidad, sea coherente con los hechos. Lo significativo es que quienes participan de ello lo perciban como cierto y les sea eficiente en términos ideáticos. En este sentido, la dominancia de Sevilla o Betis no sería medible en términos deportivo, porque, y retomo lo dicho al principio, no estamos hablando de fútbol, de resultados, ya que el juego es el pretexto, la anécdota que corporeiza otras categorías. Para ilustrarlo, paso a relatar la conversación que escuché en una tienda entre un bético y un sevillista, en la que el segundo decía que teniendo en cuenta su éxito deportivo, sus muchos trofeos europeos, dentro de unos años los niños de la ciudad serían casi todos del Sevilla. El bético se sonreía diciendo que no iba de eso la cosa, que lo del Betis no era fútbol, sino un sentimiento. Unos cuantos años después, la evidencia era clara: a pesar de la fantástica trayectoria del Sevilla y su salud y poderío económico, el Betis lo seguía superando en número de socios.

La inconmensurabilidad de que hablamos tiene que ver con el concepto antes mentado que complementa la cismogénesis en las dinámicas duales de pertenencia, el estereotipo. Sevilla y Betis movilizan universos de significado distintos, y los estereotipos que soportan se mueven en ámbitos geográficos diferentes. Por tanto, la preeminencia, siempre imposible, repito, no quedará nunca zanjada por una tabla clasificatoria o por el relumbrón de las vitrinas.

Empezando por el equipo de Nervión, el imaginario que proyecta tiene que ver precisamente con los valores de la lucha, el esfuerzo, la pelea. Esta lógica combativa, épica, viene reflejada en sus eslóganes, como, por ejemplo, Sevilla hasta la muerte. Hay que tener en cuenta que a la delantera del Sevilla que se alzó campeón de Liga en los años cuarenta se la llamaba delantera Stuka, rememorando el poderío de la aviación alemana en la Segunda Guerra Mundial. Junto al combate, otro elemento identificador es el del señorío, una suerte de distinción social, una cierta clase, por decirlo de algún modo. Será precisamente jugar en el terreno simbólico de la pelea, del enfrentamiento deportivo, de ceñirse en definitiva al sentido estricto de la lógica futbolística de la búsqueda del triunfo, lo que hará que en el contexto de fútbol nacional el Sevilla no muestre muchos rasgos singularizadores respecto a los otros clubes, salvo el evidente reconocimiento de su excelencia como equipo, incontestable en los últimos años.

En cambio, el Betis juega en otra liga conceptual. El triunfo, la victoria, no es la divisa del club de Heliópolis, su lema es Viva el Betis manque pierda. Frente a la muerte, la vida, frente a la victoria, la relativización de la misma como categoría superior y la aceptación de la eventual derrota, que no erosiona la 
propia condición y naturaleza del equipo y su afición, esa que le canta aunque último estuvieras, siempre te ve campeón.

El Betis trasciende la dimensión local y se conforma como referente, cristalización en términos deportivos de algo más, y ese algo tiene que ver con una idea, cierta o no, de Andalucía y lo andaluz. En efecto, hay una vinculación del Betis con elementos recurrentes en la cultura popular de Andalucía, como la gracia, el chiste, el humor, el quiebro en el sentido, la ridiculización de valores trascendentes como la seriedad, el sacrificio o la jerarquía. Téngase en cuenta que saber lidiar con la derrota, amoldarse a las desazones de la vida, a la injusticia de las situaciones, ha sido una constante de las clases populares de una tierra que ha arrostrado desigualdades dramáticas. Pero hacerlo sin negarse a perder la ilusión y el gozo de vivir ha sido lo más trascendente y diferencial en Andalucía. La voluntad estética, la alegría y el desparpajo caen en el imaginario del lado del Betis. En este sentido hay que entender frases célebres como la de Rogelio; míster, no corro porque correr es de cobardes. Si nos fijamos en la relevancia que en la cultura popular del sur han tenido los toros y el flamenco no es difícil ver la asociación del Betis con el toreo, ya sea Joaquín dando capotazos o la propia denominación de Currobetis, por la genialidad inconstante, esteticistas y poco esforzada del Faraón de Camas. Frente a la casta y el coraje de que con razón hace gala el himno del Sevilla, el del Betis nos habla de luz en la mañana y en la noche quejío y quiebro.

Es por todo ello que fuera de Andalucía se asocia, se quiera o no, al club verdiblanco con el estereotipo andaluz. Existe un prejuicio hacia los andaluces que los ubica en el imaginario de gente con arte y un sentido hedonista de la vida. De entrada, el andaluz tiene que ser simpático, cae en gracia, que es lo que sucede con el Betis fuera de la región. Entre otras cosas, el equipo es percibido como algo diferente de los otros clubes españoles, no es convencional, es de los más seguidos en las retransmisiones deportivas y cuenta con peñas por diversos lugares de España.

El club de Nervión, además de blasonar de señorío, se circunscribe más a la ciudad de Sevilla, y así la sevillanía es una palabra que aparece en su himno. Las peñas sevillistas, que son la mitad que las béticas, trascienden menos los límites de la ciudad y los pueblos de la provincia, es decir, de todo aquello amparado por el nombre de Sevilla. El resto de Andalucía no muestra una identificación con el club, a pesar de ser el que mayores éxitos deportivos cosecha de todos los de la región y durante mucho tiempo, haciéndole alcanzar una indudable reputación internacional. Es revelador a este respecto que hay en el resto de provincias andaluzas alrededor de 120 peñas béticas, mientras que las sevillistas frisan la treintena. Es preciso tener en cuenta también que para los habitantes de ciertas ciudades y provincias andaluzas, a pesar de ser la capital autonómica, y quizás también en parte por ello, hay un cierto desapego hacia Sevilla, a la que se adscribe más claramente al club blanco. En esta misma línea, la identificación con lo andaluz se apoya en otros dos elementos concluyentes de este universo de vinculaciones. Por una parte tenemos el adjetivo bético y el nombre Betis, que refieren a la región en tiempos romanos y al Guadalquivir, rio andaluz por antonomasia y cuya cuenca comprende a la mayoría de las provincias andaluzas. Finalmente, y poco más se puede añadir, verde y blanca es la bandera de Andalucía, a la que el propio himno ensalza. La bandera oficial del Betis no es otra que la andaluza, solo que con el escudo del club en lugar del de la comunidad autónoma.

Por todo ello, vemos cómo Betis y Sevilla se mueven en dos ámbitos distintos, aunque solapados en parte. Ambos son pilares cismogenésicos de la vida local sevillana, pero uno de ellos la trasciende y está fuertemente cargado de significaciones de la cultura andaluza. Gramaticalmente, uno es término marcado, no aplicable fuera de su ámbito estricto de designación, el otro no.

\section{Agradecimientos}

Agradezco a David Florido la lectura crítica que hizo de un primer texto del artículo y que me llevó a modificar algunas ideas. En algunas otras he perseverado a pesar de sus indicaciones. 